UDC: 811.111'276.6:159.946.4 https://doi.org/10.22190/JTESAP2103401F

Original scientific paper

\title{
QUESTIONING EAP: A CRITIQUE OF THE ENGLISH FOR ACADEMIC PURPOSES COURSES AT UNIVERSITY
}

\author{
Natalia Fedorova \\ University of Coimbra, Portugal
}

\begin{abstract}
Pre-sessional English for Academic Purposes (EAP) courses are meant to prepare international students for their undergraduate and postgraduate programmes in an English-speaking academic environment. Prospective university candidates for whom English is not the first language are required to complete a pre-sessional EAP course if their IELTS score is lower than the admissions requirements. Even though, in terms of the language requirement, the lack of language proficiency is the only reason preventing international students from entering their degree programmes directly, the course they are required to take is an EAP course rather than a General English one, hence, not directly addressing their lack of general language proficiency. In this essay I question the need to impose such a course on international students: is EAP in its current shape necessary for their success at university or is it merely a product of neoliberalism in higher education?
\end{abstract}

Key words: English for Academic Purposes, neoliberalism, academic study skills, Critical EAP

\section{INTRODUCTION}

The number of international students obtaining degrees at universities in Englishspeaking countries has been steadily increasing over the last several years before the Covid-19 pandemic. For example, in the UK alone in the 2018/19 academic year that number was 485,645, according to HESA (2020). Since international (non-EU) students have to pay twice the amount for their degree in the UK, they bring substantial revenue to the universities and the economy at large. Other English-speaking countries such as Australia are also competing for this market. This, as a result of the commercialization and commodification of universities due to neoliberalism, has created a lucrative market for pre-sessional English for Academic Purposes (EAP) courses, which aim to bridge the perceived gap between the linguistic and cultural knowledge and academic skills international students are thought to possess (or, rather, lack) prior to their study and the requirements on their academic departments. EAP courses are mandatory for those students falling short of the IELTS requirement on their target departments - most frequently ranging between 6.0 and 7.0. Whereas the emergence of EAP has led to some positive developments such as more abundant, albeit precarious and often seasonal, work

Submitted November $17^{\text {th }}, 2020$, accepted for publication March $3^{\text {rd }}, 2021$

Corresponding author: Natalia Fedorova. University of Coimbra, Portugal |E-mail: natalia.fedorova@yahoo.com 
for English teachers, the aforementioned profits for universities and the economy, and the development of research in the EAP field, there is still uncertainty as to the real shortterm and long-term benefit of EAP courses. This article intends to pose more questions than provide answers, hence being the point of departure for further research and reflection among current and prospective EAP practitioners around the world.

\section{QUESTIONING THE IELTS SCORE}

The point of departure for this discussion is questioning the basis upon which the IELTS requirement has been set and what it correlates to, especially since a student's IELTS score tends to determine the length of the required EAP instruction.

Firstly, there is no consistency as to which IELTS scores are deemed as the minimum requirement in different universities. Universities are allowed to set their own requirements but whether it is based on any evidence from the research is a big question. For example, Hyatt (2013) points out that there is a lack of knowledge among various participants in the higher education ('stakeholders' as they are called in the neoliberal world) with regards to what each IELTS score represents and correlates to. Hence, he contends, there is a strong case for raising awareness of the connection between various scores and linguistic and communicative competence. Since there are gaps in this awareness, on what basis do universities decide on the cut-off IELTS scores for prospective students? If it is based on the competencies described in detail in the Common European Framework of Reference for Languages (CEFR), why do some universities tend to set their requirements higher than the others in the same subjects? Could it be that prestigious universities set their requirements higher for the reasons other than purely research-based? This is not only the case in the English-speaking countries: there is no consistency in the IELTS requirements in the universities in the EU either, where an increasing number of degrees are taught in English: e.g. within the country of Belgium there are varying requirements for the English programmes offered - whereas KU Leuven requires a minimum of 7.0 (KU Leuven n.d.), Ghent University requires a 6.0 (Ghent University n.d.).

Secondly, it seems logical that the language level required to access knowledge of and succeed in studying various disciplines should differ, considering disciplinary differences currently widely studied and emphasised in the EAP literature. Hence, we take it for granted that those disciplines perceived as containing more complex language and requiring more substantial written and spoken output would have a higher language requirement. But the question is: has the amount and complexity of language required for a particular discipline ever been scientifically measured and then mapped onto a particular IELTS score?

Finally, going back to the relationship between IELTS scores and the pre-sessional EAP courses, it has been established that a particular IELTS score determines the number of hours of a pre-sessional study a learner needs to undertake in order to qualify for their degree programme. In practice, this means a student with a 4.5 is likely to need to undertake a full year of an EAP study to reach the requirement of a 6.5 overall. More specifically, 0.5 increase in the IELTS score has been attributed to taking a 10 -week presessional EAP course, even though the British Association of Lecturers for Academic Purposes (BALEAP), which is involved in the provision of EAP courses in the UK, states that there is no evidence in research to suggest a particular length of a pre-sessional course is equivalent to gaining a particular IELTS score (BALEAP 2012), especially, 
since many universities do not require students to retake IELTS upon the completion of presessional courses. Even then, there is no consistency in what universities advertise: according to Pearson's study (2020a) conducted in the UK, universities advertise bridging the gap of IELTS 0.5 with anything ranging between two and twenty weeks, whereas for a gap of 1.0 the average duration was 12 weeks with one institution offering as little as five weeks. The matter becomes even more complicated if we take into account the fact that any evidence of the correlation between the IELTS scores and the predicted academic performance is inconclusive (Hyatt 2013; Pearson 2020a). All this raises a legitimate question as to the science behind the decision-making process resulting in such correlations and projections.

\section{QUESTIONING THE CONTENT OF EAP COURSES}

There exist variations in the content of EAP courses, whether in-house materials or coursebooks are used, but the key mission of any EAP course is to prepare a prospective international student for the academic study at a university. The ways to achieve this and the actual goal of achieving this, however, can be questioned.

One of the essential elements of an EAP course is developing learners' academic study skills. These often include such skills as note-taking, using the feedback, effective reading strategies, independent learning, critical thinking, time management, using the library, editing, proofreading, presentation skills and others. Naturally, these skills seem indispensable at a university but the question is why an EAP course should contain these. The premise seems to be that international students are perceived to somehow lack these skills or have developed ineffective strategies prior to their study in an English-speaking environment. Much of this perception comes from the notion of difference between Western education and learners' educational background. Whilst it seems logical that there are differences in educational systems around the world, there is a risk of overgeneralisation: with international students coming from different countries, is it fair to put them all in the same 'box'? Do Chinese and Arabic students equally need instruction on critical thinking? Is it even fair, for example, to assume all Chinese students lack critical thinking skills as claimed by many researchers (e.g. Tian and Low 2011)? With regards to critical thinking and Chinese students, a fair amount of primary and secondary research has been made, with some researchers arguing that critical thinking is not an alien concept to these students (Paton 2005; Foster and Mu 2011). To what extent this side of the argument has informed the design of EAP teaching materials is not clear. What is also not clear is why the research on critical thinking among students from countries other than China has not been so extensive and what the implications of this are for those students.

Another example of difference in the study skills frequently attributed to culture and included in EAP curricula is plagiarism. Again, Asian students, Chinese in particular, are widely cited to struggle with this notion, reportedly due to Confucianism promoting open access to knowledge and neglecting the importance of textual ownership (Sowden 2005; Amsberry 2009). This informs the content of EAP courses in a way that may be a selffulfilling prophecy: based on the said premise, Chinese students are perceived to need extensive instruction on avoiding plagiarism and when, after instruction, some students are still found to commit such an act of academic malpractice, it may be seen as a sign of the persistence of the Chinese culture. However, it is controversial as to the degree to which this is due to the cultural factor: for instance, Liu (2005) insists that plagiarism is 
not and has never been a norm in the Chinese education, giving examples from the Chinese literature of where such acts have been condemned. The real reasons are then concluded to stem from Chinese students' difficulties with language and writing skills rather than the cultural stereotypes based on anecdotal evidence. Again, has such research informed the content of EAP courses or does it continue to portray Chinese students as deficient in the matters of academic integrity?

Also, speaking of academic study skills, they are also not homogenous: whereas there may be a cultural debate surrounding the skills of critical thinking and plagiarism, such skills as using the library, editing, proofreading, referencing, and note-taking may vary among individuals and thus may benefit students of any nationality and educational background. Indeed, the development of such study skills is offered even for local students with English as their L1, for instance, by such institutions as the University of Bristol (University of Bristol n.d.) which offers the Study Skills service open for all and Cardiff University (Cardiff University n.d.) offering the same kind of study support for all students, home and international. Even UCAS (Universities and Colleges Admissions Service) (UCAS n.d.), which is a centralised service through which prospective undergraduate students in the UK apply for universities, offers the Study Skills Guides on its website, designed for everyone to use. By looking through the topics covered in the three examples given here, such study skills as academic essay writing, editing and proofreading, time management, presenting an argument, academic reading, group work, critical thinking, amongst others, are beneficial even for students whose educational background is from an English-speaking country, raising a question why international students have to study these separately on EAP courses.

Whereas study skills tend to be paid some attention on EAP courses, some other key areas could be developed more systematically. There is a growing body of research dedicated to disciplinary differences in terms of genre, vocabulary, the expression of authorial stance and others. The extent to which this research informs the content of many EAP courses is questionable. Firstly, English for Specific Academic Purposes (ESAP) courses, designed to help learners succeed in their respective subjects rather than the academic study in general, tend to mostly be run in the summer term where student numbers are high enough to enable splitting the student cohort into separate groups according to their disciplines. Is it possible to sufficiently raise each student's awareness of the characteristics of their target discourse community in just ten weeks (with the actual input often lasting less than this due to introduction in the first week and assessment in the last two weeks)? Secondly, non-specialist teachers' awareness of disciplinary differences prior to their work on such courses needs further research: as a rule, summer courses are intensive and do not allow time allocation for seasonal teachers' research and professional development.

Finally, one side of the argument is the quality of the content of EAP courses; another is the actual reasoning behind preparing international students for the study at a Western university. This may be a good intention but no education is apolitical. Is imposing 'Western' rules on international students and the need for them to adapt, without questioning, to the conventions of a university and the particular discourse community not a form of cultural imperialism? Is university a place where norms are acquired and transmitted or a place for critical inquiry? Is the role of EAP courses indoctrination into those rules? Does Western academia have the right to claim critical thinking as its core, pointing to its lack among international students, when EAP courses (possibly, unintentionally) tend to perpetuate the divide between home and international students, whilst trying to mould the latter into shape, 
stripping them of their linguistic and cultural identity? All these may seem to be questions too detached from a daily routine of an EAP practitioner but they echo the concept of Critical EAP coined by Benesch (2001), designed to encompass the critical inquiry into power relations within the academia.

\section{QUESTIONING THE EFFECTIVENESS OF EAP COURSES}

Even though there have been studies attempting to measure the effectiveness of EAP courses in terms of learners' progress in their academic and language skills, as well as the skills transfer onto their subsequent degree studies and thus the long-term impact of EAP, none of these studies have been entirely conclusive. Pearson (2020b) has recently investigated the evidence from all the currently available UK-based studies and the result of this discussion raises more questions.

The evidence discussed by Pearson (2020b) includes such positive outcomes as the improvement in academic skills, although such improvement is said to be unremarkable. This has been found particularly evident in learners who graduated from their pre-sessional EAP courses with borderline marks - they tended to retain the same level of proficiency throughout their graduate study, resulting in the need to seek extension or resubmission and taking longer to complete their studies. Overall, students whose IELTS scores originally met the requirements of their degree programmes, thus allowing them direct entry onto their courses bypassing any pre-sessionals, were more likely to achieve academic success than those who fell short of the requirements and had to undertake the EAP courses. Thus, it appears that taking an EAP course may not be a gateway to academic success, which should be communicated clearly to prospective students (Pearson 2020b).

In terms of language development, there was a particular concern voiced by the students themselves - there was an initial expectation of more targeted language development on the course which was not met (Pearson 2020b). This may not be simply due to an ambiguous naming of a particular EAP course, as suggested by Pearson (2020b), or the fact that learners might not have experienced such a type of course before. It seems rather natural to expect the targeted and systematic improvement of one's general language skills, given that the reason for the denial of a direct entry onto their programmes is falling short of the language requirement. It is no wonder, then, why international students may perceive the lack of progress in their language level. This raises a question whether learner needs are met on EAP courses. It is noteworthy that, unlike on General English courses, learner needs on EAP courses are pre-determined and completely laid-out in the curricula. On certain EAP programmes tutors are required to follow the course materials without making any significant changes and only allowing for the discussion of individual learner needs during short one-toone consultations. It seems questionable whether it is a completely fair approach: essentially, EAP learners have no choice as to what they study and would probably be too apprehensive about negotiating course content, being held hostage by the outcome of their pre-sessional course.

One example of EAP courses possibly falling short of learners' expectations is the inclusion of the grammar instruction into the curricula. Whereas vocabulary is widely addressed in EAP classes as well as research, for example, in the form of a genre analysis and the study of common core and subject-specific corpora, grammar is addressed far less and is often left on the periphery. For example, Tribble (2009) found in his survey of the 
EAP writing coursebooks that none of them addressed the issue of grammatical accuracy in academic writing. This is, perhaps, due to the dominance of the Content-Based Instruction in EAP provision which is concerned with teaching language through the context of a particular subject (Landry 2019). Brinton and Holten (2001), however, criticise this approach and argue in favour of incorporating a more systematic treatment of grammar into an EAP classroom, shifting the focus from content onto language. Learners themselves consider grammar important for academic study, particularly for academic writing (Leki and Carson 1994; Gardiner 2012) and have shown to be in favour of more substantial coverage of grammar on pre-sessional courses. Despite this, there is a notable absence of the explicit reference to 'grammar' in the BALEAP 'Can Do' Framework for learners (BALEAP n.d., p.7); however, there are competencies such as writing 'clearly without meaning being obscured', demonstrating 'language knowledge and control/accuracy' which includes 'syntax' (that is, sentence structure and word order), and understanding 'subtleties/nuances of language'. With the exception of syntax, it is, however, open to interpretation to what extent grammar plays a role in developing these competencies and which grammatical items may be essential to focus on in EAP classes. What is clear though is that the lack of research in this matter and insufficient inclusion of grammar in EAP courses may present a missed opportunity to meet learners' language learning needs.

\section{CONCLUSION}

The questions raised in this article present obvious directions for further research. Without claiming to possess any definitive answers to the questions raised, I could propose certain measures to act as a point of departure for positive change.

- it could be worth re-assessing the real differences between the level of development of academic study skills among international students prior to undertaking the EAP courses and home students, to whom study skills support is optional. It could perhaps lead to realising more commonalities in the needs and challenges among home and international students. With such an eventuality, an opportunity to re-imagine EAP courses could present itself: perhaps, both home and international students could develop these skills together, addressing another widely cited concern among international students - lack of mingling and making friends with home students.

- in the spirit of Critical EAP, all 'stakeholders' should question the 'Western' standards they perpetuate and consider the issues of equality, diversity of student voices, inclusivity, and linguistic and cultural identity in academia. This could lead to rethinking the content of EAP courses and redefining the role of EAP.

\section{REFERENCES}

Amsberry, Dawn. 2009. "Deconstructing Plagiarism: International Students and Textual Borrowing Practices". The Reference Librarian 51 (1): 31-44. https://doi.org/10.1080/ 02763870903362183

BALEAP. 2012. "BALEAP Guidelines on English Language Tests for University Entry". BALEAP. https://www.baleap.org/wp-content/uploads/2016/04/BALEAP Guidelines on English Language Tests_for_University AGM_v19_May_2012.pdf 
BALEAP. n.d. "BALEAP Can Do Framework: Competency Statements for International Students (Master's Level)". BALEAP. https://www.baleap.org/wp-content/uploads/2016/ 04/Can_Do_Framework_with_sample_activities_April_2013.pdf

Benesch, Sarah. 2001. Critical English for Academic Purposes: Theory, Politics, and Practice. Mahwah, NJ: Lawrence Erlbaum Associates.

Brinton, Donna M., and Christine A. Holten. 2001. "Does the Emperor Have No Clothes? A Re-Examination of Grammar in Content-Based Instruction." In Research perspectives on English for Academic Purposes, edited by John Flowerdew and Matthew Peacock, 239-251. Cambridge: Cambridge University Press.

Cardiff University. n.d. "Academic Study Skills". Cardiff University. https://www. cardiff.ac.uk/study/student-life/learning-support/academic-skills-classes

Foster, Monica, and Yufeng Mu. 2011. The Use of Critical Thinking by Chinese Students in Higher Education. Edinburgh: Queen Margaret University.

Gardiner, John. 2012. "Student Attitudes to EAP Grammar Instruction". Cambridge Research Notes 48: 11-17.

Ghent University. n.d. "Levels of Language Proficiency". Ghent University. https://www.ugent.be/prospect/en/administration/application/requirement/languagereq uirements/proficiency/proficiency.htm\#LanguageproofsforEnglishprogrammes

Higher Education Statistics Agency (HESA). 2020. "Higher Education Student Statistics: UK, 2018/19”. HESA. https://www.hesa.ac.uk/news/16-01-2020/sb255-highereducation-student-statistics

Hyatt, David. 2013. "Stakeholders' Perceptions of IELTS as an Entry Requirement for Higher Education in the UK". Journal of Further and Higher Education 37 (6): 844863. https://doi.org/10.1080/0309877X.2012.684043

KU Leuven. n.d. "Prerequisites for Degree Seeking Students". KU Leuven. https://eng. kuleuven.be/en/study/prospective-students/degree-seeking-students/prerequisites-fordegree-seeking-students

Landry, Michael Henry. 2019. "The Efficacy of Teaching Independent Study Skills within English for Academic Purposes Programs". BC TEAL Journal 4 (1): 1-12. https://doi.org/10.14288/bctj.v4i1.316

Leki, Ilona, and Joan G. Carson. 1994. "Students' Perceptions of EAP Writing Instruction and Writing Needs across the Disciplines”. TESOL Quarterly 28 (1): 81-101. https://doi.org/ $10.2307 / 3587199$

Liu, Dilin. 2005. "Plagiarism in ESOL Students: Is Cultural Conditioning Truly the Major Culprit?" ELT Journal 59 (3): 234-241. https://doi.org/10.1093/elt/cci043

Paton, Michael. 2005. "Is Critical Analysis Foreign to Chinese Students?" In Communication skills in university education: The international dimension, edited by Emmanuel Manalo and Glenis Wong-Toi, 1-11. Auckland: Pearson Education.

Pearson, William S. 2020a. "Mapping English Language Proficiency Cut-Off Scores and Pre-Sessional EAP Programmes in UK Higher Education". Journal of English for Academic Purposes 45: 1-11. https://doi.org/10.1016/j.jeap.2020.100866

Pearson, William S. 2020b. "The Effectiveness of Pre-Sessional EAP Programmes in UK Higher Education: A Review of the Evidence". Review of Education 8 (2): 420-447. https://doi.org/10.1002/rev3.3191

Sowden, Colin. 2005. "Plagiarism and the Culture of Multilingual Students in Higher Education Abroad". ELT Journal 59 (3): 226-233. https://doi.org/10.1093/elt/cci042 
Tian, Jing, and Graham David Low. 2011. "Critical Thinking and Chinese University Students: A Review of the Evidence". Language, Culture and Curriculum 24 (1): 6176. https://doi.org/10.1080/07908318.2010.546400

Tribble, Christopher. 2009. "Writing Academic English - A Survey Review of Current Published Resources”. ELT Journal 63 (4): 400-417. https://doi.org/10.1093/elt/ ccp073

UCAS. n.d. "Study Skills Guides”. UCAS. https://www.ucas.com/undergraduate/studentlife/study-skills-guides

University of Bristol. n.d. "Study Skills". University of Bristol. https://www.bristol.ac.uk/ students/your-studies/study-support/study-skills/ 